\title{
Analysis of Wear Mechanisms and Chip Morphology During Machining of Tool Steel Using TiAISiCrN-Coated WC-Co Ball end Mills
}

\section{Farooq Ahmed}

Dhofar University

S. Thirumalai Kumaran ( $\nabla$ thirumalaikumaran@yahoo.com )

Kalasalingam Academy of Research and Education

\section{Furqan Ahmad}

Dhofar University

\section{Research Article}

Keywords: ball end milling, tool geometry, tool wear, chip morphology, surface roughness.

Posted Date: January 25th, 2022

DOI: https://doi.org/10.21203/rs.3.rs-1144076/v1

License: (c) (1) This work is licensed under a Creative Commons Attribution 4.0 International License.

Read Full License 


\section{Abstract}

Machining of difficult-to-cut materials with high surface quality is a challenging task that requires a precise machining approach with an efficient cutting tool. Among the tool performance evaluation parameters, rate of wear, chip morphology and surface quality are the vital aspects to establish a relationship between the input conditions and the machining quality. In this study, tool geometrical parameters i.e. rake, clearance and helix angles were selected to analyse the effect of geometry on wear behavior and the chip morphology during the ball end milling of tool steel. Increase in rate of wear with machining length was analysed based on the different tool geometry combinations. Tool geometry with rake angle $3^{\circ}$, clearance angle $10^{\circ}$ and helix angle $32^{\circ}$ was found to have least wear length at $56 \mu \mathrm{m}$. The study provides basis for the selection of geometry parameters considering the wear mechanisms and the chip morphology. The influence of the change in tool geometry on surface quality was also analysed and reported.

\section{Introduction}

Cutting performance of the tool during machining of difficult-to-cut materials depends on several factors such as tool material [1, 2], protective coating applied on the tool $[3,4]$ and the machining conditions $[5,6]$. In addition to that, Geometry of the tool have significant effects on the efficiency of the cutting process and needs carefull analysis. Tool geometry parameters influencing the cutting performance of the ball end mill are rake angle, clearance angle, helix angle, nose radius, inner circle diameter and cutting-edge radius (Figure 1). Each factor has its specific effect on the performance efficiency of tool and hence its value is selected based on work material properties, machining conditions, surface finish required etc. Several researchers have studied the effect of tool geometry parameters proposed combination of geometrical factors to get an optimum tool life and machining results [7-10].

In-situ measurement of out-put response such as cutting force, heat generated is a difficult task and requires a robust and accurate data recording system. Tool wear and surface roughness, on the other hand are measured ex-situ and hence the data thus obtained is more reliable to evaluate the effect of machining conditions. In addition to that, as ball end milling is an interrupted contact of the tool edge with the work surface further makes the thorough wear analysis an important aspect to achieve cost effective machining process.

Considering the above-mentioned points, numerous researchers have analysed the influenceof change in cutting conditions on the tool wear and machining quality. Vipindas and Mathew et al. [3] studied the wear behaviour of TiAIN coated WC tools along with the machined surface quality during micro end milling of Ti6Al4V and adhesive wear was found to be the major tool failure mechanism for all themachining conditions. In another study, Ren et al. [10] performed experiments with six different carbide grade tools to compare the cutting signature and tool wear. They performed the multi objective optimization to identify the most significant factors and found K44 carbide tool without protective coating to be best suited for the cutting process.In a similar experimental study, Rakesh and Datta [11] 
analyzed the effect of cutting speed on chip morphology and mechanisms of tool wear during the machining of Inconel 718 by WC tool. Chip morphology including features of chip cross section, free surface of chip and chip reduction coefficient by the effect of speed was studied. Abrasion, adhesion, coating delamination, flank wear, crater wear and notch wear were potential identified wear mechanisms.

Although, the above mentioned and many other similar studies [13-15] have investigated the effect of machining/geometry conditions on tool wear and surface quality. However, evaluation of cutting performance of tool over a wide range of input parameters through machining is a tedious task as it takes a lot of time and cost to perform the tests. Additionaly, experimental results provide a typical relationship between the machining conditions and the output responses that may not be valid for a different machining scenario. However, identification of potential tool wear mechanisms and the wear behaviour based on the machining and tool geometry conditions can be used to predict the behavior of tool with a certain level of accuracy and optimize the tool life. Additionaly, chip morphology and the machined surface quality reflects the machining process and helps in predicting the cutting forces and the energy required for material removal [15].

During the current experimental study, ball end milling was performed to analyse the effect of tool geometry parameters on the wear behaviour, surface roughness and chip morphology. The idea is to establish a relation between the wear type and the corresponding geometrical conditions, which can be used to predict the wear behaviour of ball end mills for a particular set of tool geometry conditions.Surface roughness and chip morphology were also evaluated to determine the influence of variation of geometry parameters. The findings related to chips and surface quality with known input conditions, can be later used to forecast the machining performance of tool.

\section{Experimental Details}

Machining tests were performed on a CNC-based vertical machining centre equipped with 20,000rpm spindle and 3-axis degree of freedom (Figure 2). The workpieces were rectangular blocks of AISI H13 (52 HRC) tool steel with a machining area of $60 \times 20 \mathrm{~mm}$ held in a jig with the surface to be machined inclined at $25^{\circ}$ (Figure 2-A'). Cutting conditions were selected as cutting speed of 20,000 rpm, feed rate of $0.1 \mathrm{~mm} / \mathrm{rev}$, depth of cut of $0.1 \mathrm{~mm}$ and width of cut $0.4 \mathrm{~mm}$. Machining was done under dry conditions to avoid the heat loss with the coolant. All the experiments were repeated three times and the average value of the results was presented with error bar to show the spread of result data.

Geometry of the tool for machining tests was selected based on the results of previous finite element based study performed by the authors to optimize the tool geometry parameters[16]. From the 25 different geometrical combinations, nine were selected based on the rank of grey relational gradient (Table 1). Other specifications includes diameter of the tool as $2 \mathrm{~mm}$, tool material as WC-8\%Co with $6 \mu \mathrm{m}$ thick single-layered protective coating of TiAlSiCrN.

Table 1 Tool geometries selected based on grey relational analysis 


\begin{tabular}{|c|c|c|c|c|}
\hline \multirow{2}{*}{ Geo. No. } & \multicolumn{3}{|c|}{ Geometry factors } & \multirow{2}{*}{ GRG ranking } \\
\cline { 2 - 4 } & Rake angle $(\alpha)$ & Relief angle $(\beta)$ & Helix angle $(\gamma)$ & \\
\hline Geo.11 & 0 & 10 & 28 & 1 \\
\hline Geo. 23 & 6 & 20 & 24 & 2 \\
\hline Geo. 16 & 3 & 10 & 32 & 3 \\
\hline Geo. 19 & 3 & 25 & 24 & 12 \\
\hline Geo. 5 & -6 & 30 & 36 & 13 \\
\hline Geo. 20 & 3 & 30 & 28 & 14 \\
\hline Geo. 9 & -3 & 25 & 36 & 23 \\
\hline Geo. 3 & -6 & 20 & 28 & 24 \\
\hline Geo. 10 & -3 & 30 & 20 & 25 \\
\hline
\end{tabular}

Increase in wear was measured by examining the tool using industrial CCD microscope (Camscope-ITplus 4.06-Sometech) at the regular interval of $11.25 \mathrm{~m}$ cutting length and under the scanning electron microscope (SEM) at the end of total machining length. Before examining under the SEM, the tools were cleaned ultrasonically with acetone to remove any impurity. The images obtained through industrial microscope and SEM, were analysed by image-pro software for the quantification of wear in terms of distance of deepest point of permanent deformation from the cutting edge of the tool. Chips were collected at the end of machining length and examined under the SEM to identify the morphology. Machined surface quality was measured in terms of arithematic roughness value $(R a)$ by using portable surface roughness tester (Mitutoyo SJ310) and evaluated with the increase in machining length.

\section{Results And Discussion}

\subsection{Effect of tool geometry on tool wear}

Wear measurement was initiated at $30 \mathrm{~m}$ length of cut followed by examination of tool in steps of $11.25 \mathrm{~m}$ till the end of machining length. Figure 3 illustrates the trend of increase in tool wear with the length of machining. Images of the worn out tool included in the graphical representation shows the progression in length of wear at the flank face of the tools and the extent of notch wear at end of flank face for geometry 10 . Although, the trend of increase in wear amount is nearly identical under the same machining conditions, but the large difference in extent of the wear, point to the effect of tool geometry parameters.

Figure 4-6 illustrates the types of wear observed during the examination of tools under SEM. Generally, tool failure mechanisms can be categorized as wear and fracture with abrasion, adhesion of work material, rupture of protective coating and notch wear as the type of wear formation as mentioned also by Rakesh et al. [22] and Devillez et al. [23]. Abrasive wear observed in Figure 4 (b), Figure 5 (b-c) and Figure $6(b-c)$ is largely due to the rubbing of the flank face with the machined surface and the flow of chips over the rake face forming scratches in the direction of chip flow. Additionaly, abrasion of flank face also takes place due to hard-grained particles present at the top layer the work surface. The amount of 
abrasive wear is based on the clearance and rake angle of the tool. It is clearly seen from the figure that the amount of abrasion wear is higher for tool with negative rake angle, which is due to the larger toolchip contact length. However, large helix angle provides ease to the exit of chip from shear zone without any significant contact with the tool body that limits the rate of wear.

Heat generated during high-speed milling reaches up-to $600^{\circ} \mathrm{C}$ leading to the fusion of work material flakes over the cutting edge of tool [18]. During machining with negative rake angle tool, uncut chips thickness becomes larger than the edge radius and creates the ploughing effect with flank face rubbing with the work surface leading to tool wear in the form of adhesion of chip at the flank face [3]. Figure 4 (a), Figure 5 (c) and Figure 6 (c) shows the existence of adhered work material at the rake and flank face of the tool. EDS analysis was performed to confirm the adhesion of work material at the tool tip as shown in Figure 7. Referring to the geometries of the tools examined by SEM, it can be established that large clearance angle and helix angle along with the positive rake angle plays crucial role in reducing the chances of adhesion. Higher degree of helix angle ease the escape of chip from the cutting zone and hence possibilities of adhesive wear gets reduced. On the other hand, as reported by Biksa et al. [19] during the high-speed machining of hard materials, adhesion of work material particle acts as a protective shield by securing the tool surface from the abrasion marks due to rubbing of tool edge.

Another important factor of tool failure as observed from Figure 6 (a) is the tearing of protective coating. During machining, work material adhered at the edge gets detached due to the high pressure and initiates chipping off the tool material with the tearing of coating. The same phenomenon was also reported by Hao et al. [20]. Conversely, Ibrahim et al. [21] stated that the rate of adhesion is increased after the development of cracks in the coating layer. Thus, the tool geometries with negative rake angle generating ploughing effect and positive rake angle with large tool-chip contact length causing large cutting forces have more chances of coating breakage/delamination.

Figure 4 (c) shows another mode of tool failure as fracture of the edge generally observed during the high-speed machining depends directly on cutting force and the geometry of the tool. Higher degree of clearance angle reduces the strength of cutting edge along with the increase in cutting forces generated due to the negative rake angle that increase the chances of tool failure in the form of edge fracture. The results obtained during the wear analysis by Ren et al. [10] also shows the similar tendency of wear rate with change in tool geometry. Wear in the form of notch at the flank face as shown in Figure 4 (c) and Figure 6 (b) is largely due to the uneven contact of the tool edge with the work surface during machining. This phenomenon was also observed by Akhter et al. [22], however they explained it as the flow of hardened chips rub over the tool surface causing the notch formation.

Figure 8 (a) \& (b) shows the variation in wear amount with the machining length and tool geometries respectively. It is evident from the Figure 8 (a) that the tendency of increase in wear amount is almost the same for all the tool geometries with the increase in length of cut, howeverthere is large difference in final wear amount with change in geometrical parameters (Figure 8b). As observed from the figure, geometries with negative rake angle i.e. geometries 3, 5, 9 and 10 have large amount of tool wear. This is due to the 
ploughing effect while machining with negative rake tools resulting in abrasion of flank face. Thus, it can be estabilished that during high-speed machining of difficult-to-cut materials, higher degree of positive rake angle and negative rake angle have more chances of tool failure in terms of fracture or chipping and adhesion wear respectively. This can be verified from the results, as geometry 16 and 11 with $3^{\circ}$ and $0^{\circ}$ rake angles were found to have lowest amount of tool wear. Similar wear behavior was reported by Jian $\mathrm{Ma}$ et al. [23] which states that using small rake angle enhances the tool life by increase in tool-chip contact length and the corresponding decrease in cutting force and tool temperature.

\subsection{Surface roughness}

Figure 9 shows the surface roughness measurement scheme and the as-obtained $R z$ value distribution graph. Arithematic value of roughness is expressed as the change in height of the machined surface relative to a base line. Analysis of the machined surface quality in terms of roughness is an important aspect to evaluate the friction, wear, lubrication behaviour of the surface.

Figure 10 shows the surface roughness distribution in the feed direction with the change in tool geometry. Three points were taken on the machined surface, to measure the surface roughness for each cutting condition and the averaged value is presented in the graph. The results clearly indicate that the trend followed by the roughness variation to the wear variation. Geometry 16 was found to be showing the best cutting performance in terms of surface roughness $(2.9 \mu \mathrm{m})$. Cutting tools exhibiting large rate of wear, were found to be having poor surface quality. It can be explained in terms of breakage of tool cutting edge, causing irreversible machining surface damage. Deformation behavior of the work materialis also an important factor as it influences the plastic deformation index and the brittle mode of material removal mechanism starts appering, resulting in increase in surface irregularity. The worst finish was obtained with the tool geometry $3(4.3 \mu \mathrm{m})$ having large negative rake angle causing the ploughing effect during machining and hence affecting surface quality.

\subsection{Chip morphology}

Geometry of the chip can be evaluated based on the tool-work engagement zone that depends on the cutter geometry. Figure 11 (a-b) illustrates the basic theoretical and experimental chip shape as generated under the normal machining conditions during ball end milling. Tool with sharp cutting edges without any wear, engages with the work material along theoretical profile that is with the start and exit of tool-work engagement zone. However, with the change in machining conditions i.e. tool wear or machining with negative rake angle tool, geometry of the chips start shifting from the theoretical shape.

Figure 12 shows the chips produced with the change in tool geometry parameters. During ball end milling the chips are produced in small conical shaped fragments due to intermittent cutting. It is clearly seen from the figure that the chips produced with the tools having lower rate of wear have smooth free surface with the shape approximately similar to the theoretical shape of the chips formed during ball end milling. With the increase in amount of wear, shape of the chips start being shifted with the formation serrations and fusion of multiple chips together. 
Figure 12 shows the chips collected at the end of $75 \mathrm{~m}$ length of machining and observed by electron microscope. It can be clearly seen that the chips formed while machining with tool geometry 16 are close to the ideal chip shape. This can be explained by the least amount of wear and absence of fractured tool edge and hence the effect of wear and friction force on the chip morphology remains negligible. However, tools with geometry 19 and 9 , under the same machining conditions and length of cut have more wear amount, that causes a rapid increase in cutting vibrations and friction force resulting in formation of serrations at the edge of chips. Serration of chips due to tool wear was also reported by Zhu et al. [14], during their study of influence of tool wear on chip morphology. Hou and Komanduri [24] also described the phenomenon of chip serration as the effect of instability in thermo-mechanical behavior of work material during machining. This instability is largely due to the friction force and heat dissipation capacity of worn out tool edge. In addtition to that, formation of multiple chips joined together can also be observed from SEM images. This can be explained by the presence of notch wear at the edge of tool, which results in incomplete removal of chip from the shear zone leaving the chip still attached to the work piece and as the succeeding flute shears the next chip, it gets attached to the previously formed chip and hence results in formation of co-joined chips as observed in Figure 11 (c). Similar phenomenon was reported by Kasim et al. [13] during their study related to cooling conditions. Cutting vibrations due to tool wear also causes the development of cracks in the chips.

Figure 13 (a-c) shows the free surface of the chips produced with different tool geometries. The side flow of material during chip formation can be noticed for the chip shown in Figure $13(a, b)$. With change in geometry of the tool, the machining conditions tends to change and causes increase in the cutting temperature and causes large plastic deformation. Hence, chips produced under stable machining conditions and normal amount of cutting have smooth surface and near ideal chip shape.Formations of serrations as observed at the edge of chips illustrated in Figure 15 (c) indicates the unstable machining conditions. This type of chips are formed primarily due to increase in cutting forces while machining with the worn out tool. Rakesh and Datta [11] explained the formation of serrations with large included angle because of the plastic instability and strain localization which causes increase in shear band thickness.

From the analysis of chip shapes and morphology it can be concluded that tool geometry parameters have significant effect on the chip formation and thus machining performance. Positive rake angle produces smooth chip shapes and facilitates chip flow from the tool-work interface. Whereas, tool with negative rake angle due to the ploughing effect produces serrated chips fused together under high temperature and pressure. These cutting conditions and instable chip shape affects the rake face of the tool and machined surface quality while flowing out of the cutting zone. Large helix angle also increases the ease in chip flow thus lowering the heat due to friction as the tool-chip contact length gets reduced. Wu et al. [25] noticed the comparable behavior during analysis of effect of geometry parameters of conventional micro end mill.

\section{Conclusions}


Ball end milling experiments were performed with the objective of analyzing the effect of tool geometry parameters on tool wear and chip morphology. WC-Co based ball mills with different geometrical combinations were selected for the machining of AISI-H13 tool steel. Following conclusions can be drawn based on experimental results:

- During machining tests, tools were observed to be failed in the form of adhesion wear, abrasive wear, notch formation, tearing of coating and fracture at the edge with abrasive wear at the flank face common to all tool geometrical conditions.

- Negative rake angle and higher degree of positive rake angle were found to be increasing the cutting forces and tool temperature. To machine the material with brittle behavior, lower degrees of positive rake angle are recommended.

- Tools with large clearance angle were found to have more chances of catastrophic failure due to reduction in strength at the edge.

- Tool geometry with higher rate of wear was observed to be producing chips fused together with serrations at the edge. This characteristic can be used as reference to predict the tool wear conditions and machining performance of the tool by simply observing the chip morphology.

\section{Declarations}

The authors declare that no funds, grants, or other support were received during the preparation of this manuscript.

\section{References}

[1] P. Gao, Z. Liang, X. Wang, T. Zhou, and S. Li, "Effects of different tool materials on tool wear of cemented carbides micro end mill," pp. 107-110, 2017.

[2] F. Ahmed, T. J. Ko, J. Lee, Y. Kwak, and R. Kurniawan, "The effect of tool material grain size on the machining process in ball end milling," Int. J. Adv. Manuf. Technol., vol. 106, no. 9-10, pp. 4411-4421, 2020, doi: 10.1007/s00170-020-04925-7.

[3] V. K and J. Mathew, "Wear behavior of TiAIN coated WC tool during micro end milling of Ti-6Al-4V and analysis of surface roughness," Wear, vol. 424-425, no. February, pp. 165-182, 2019, doi:

10.1016/j.wear.2019.02.018.

[4] G. Skordaris et al., "Effect of the crystallinity of diamond coatings on cemented carbide inserts on their cutting performance in milling," CIRP Ann., vol. 68, no. 1, pp. 65-68, 2019, doi:

10.1016/j.cirp.2019.04.056.

[5] K. Vipindas, B. Kuriachen, and J. Mathew, "Investigations into the effect of process parameters on surface roughness and burr formation during micro end milling of TI-6AL-4V," Int. J. Adv. Manuf. Technol., vol. 100, no. 5-8, pp. 1207-1222, 2019, doi: 10.1007/s00170-016-9210-3. 
[6] F. Ahmed, T. J. Ko, R. Kurniawan, and Y. Kwack, "Machinability analysis of difficult-to-cut material during ultrasonic vibration-assisted ball end milling," Mater. Manuf. Process., vol. 36, no. 15, pp. 17341745, 2021, doi: 10.1080/10426914.2021.1944194.

[7] C. Hu, K. Zhuang, J. Weng, X. Zhang, and H. Ding, "Cutting temperature prediction in negative-rakeangle machining with chamfered insert based on a modified slip-line field model," Int. J. Mech. Sci., vol. 167, no. July 2019, p. 105273, 2020, doi: 10.1016/j.ijmecsci.2019.105273.

[8] Y. Cheng, J. Yang, C. Qin, and D. Zuo, "Tool design and cutting parameter optimization for side milling blisk," Int. J. Adv. Manuf. Technol., vol. 100, no. 9-12, pp. 2495-2508, 2019, doi: 10.1007/s00170-0182846-4.

[9] J. W. Ma, Z. Y. Jia, G. Z. He, Z. Liu, X. X. Zhao, and F. Z. Qin, "Influence of cutting tool geometrical parameters on tool wear in high-speed milling of Inconel 718 curved surface," Proc. Inst. Mech. Eng. Part B J. Eng. Manuf., vol. 233, no. 1, pp. 18-30, 2019, doi: 10.1177/0954405417716495.

[10] J. Ren, Z. Zhai, K. Shi, J. Zhou, J. Yang, and J. Cai, “Tool determination and geometry parameter optimization of carbide tool in high-speed milling of third-generation y-TiAl alloy," J. Brazilian Soc. Mech. Sci. Eng., vol. 40, no. 10, 2018, doi: 10.1007/s40430-018-1408-x.

[11] M. Rakesh and S. Datta, "Machining of Inconel 718 Using Coated WC Tool: Effects of Cutting Speed on Chip Morphology and Mechanisms of Tool Wear," Arab. J. Sci. Eng., vol. 45, no. 2, pp. 797-816, 2020, doi: 10.1007/s13369-019-04171-4.

[12] K. Vipindas, K. N. Anand, and J. Mathew, "Effect of cutting edge radius on micro end milling: force analysis, surface roughness, and chip formation," Int. J. Adv. Manuf. Technol., 2018, doi:

10.1007/s00170-018-1877-1.

[13] M. S. Kasim et al., "Chip morphology in ball nose end milling process of nickel-based alloy material under MQL condition," Int. J. Adv. Manuf. Technol., pp. 4621-4625, 2019, doi: 10.1007/s00170-01903948-z.

[14] Z. Zhu, J. Sun, J. Li, and P. Huang, "Investigation on the influence of tool wear upon chip morphology in end milling titanium alloy Ti6Al4V," Int. J. Adv. Manuf. Technol., vol. 83, no. 9-12, pp. 1477-1485, 2016, doi: 10.1007/s00170-015-7690-1.

[15] H. Sonawane and S. S. Joshi, "Modeling of chip geometry in ball-end milling of superalloy using strains in deformed chip (SDC) approach," Int. J. Mach. Tools Manuf., vol. 130-131, no. November 2017, pp. 49-64, 2018, doi: 10.1016/j.ijmachtools.2018.03.005.

[16] F. Ahmed, T. J. Ko, L. Jongmin, Y. Kwak, I. J. Yoon, and S. T. Kumaran, "Tool Geometry Optimization of a Ball End Mill based on Finite Element Simulation of Machining the Tool Steel-AISI H13 using Grey 
Relational Method," Int. J. Precis. Eng. Manuf., vol. 22, no. 7, pp. 1191-1203, 2021, doi: 10.1007/s12541021-00530-0.

[17] A. Devillez, F. Schneider, S. Dominiak, D. Dudzinski, and D. Larrouquere, "Cutting forces and wear in dry machining of Inconel 718 with coated carbide tools," Wear, vol. 262, no. 7-8, pp. 931-942, 2007, doi: 10.1016/j.wear.2006.10.009.

[18] F. Kone, C. Czarnota, B. Haddag, and M. Nouari, "Finite element modelling of the thermo-mechanical behavior of coatings under extreme contact loading in dry machining," Surf. Coatings Technol., vol. 205, no. 12, pp. 3559-3566, 2011, doi: 10.1016/j.surfcoat.2010.12.024.

[19] A. Biksa et al., "Wear behavior of adaptive nano-multilayered AlTiN/MexN PVD coatings during machining of aerospace alloys," Tribol. Int., vol. 43, no. 8, pp. 1491-1499, 2010, doi: 10.1016/j.triboint.2010.02.008.

[20] Z. P. Hao, Y. H. Fan, J. Q. Lin, and Z. X. Yu, "Wear characteristics and wear control method of PVDcoated carbide tool in turning Inconel 718," Int. J. Adv. Manuf. Technol., vol. 78, no. 5-8, pp. 1329-1336, 2015, doi: 10.1007/s00170-014-6752-0.

[21] G. Akhyar Ibrahim, C. H. Che Haron, J. Abdul Ghani, A. Y. M. Said, and M. Z. Abu Yazid, "Performance of PVD-coated carbide tools when turning inconel 718 in dry machining," Adv. Mech. Eng., vol. 2011, 2011, doi: 10.1155/2011/790975.

[22] W. Akhtar, J. Sun, P. Sun, W. Chen, and Z. Saleem, "Tool wear mechanisms in the machining of Nickel based super-alloys: A review," Front. Mech. Eng., vol. 9, no. 2, pp. 106-119, 2014, doi: 10.1007/s11465014-0301-2.

[23] J. W. Ma, Z. Y. Jia, G. Z. He, Z. Liu, X. X. Zhao, and F. Z. Qin, “Influence of cutting tool geometrical parameters on tool wear in high-speed milling of Inconel 718 curved surface," Proc. Inst. Mech. Eng. Part B J. Eng. Manuf., 2019, doi: 10.1177/0954405417716495.

[24] Z. B. Hou and R. Komanduri, "Modeling of the thermomechanical Shear Instability in Machining," Science (80-. )., vol. 39, no. 11, 1997.

[25] T. Wu, K. Cheng, and R. Rakowski, "Investigation on tooling geometrical effects of micro tools and the associated micro milling performance," Proc. Inst. Mech. Eng. Part B J. Eng. Manuf., vol. 226, no. 9, pp. 1442-1453, 2012, doi: 10.1177/0954405412449229.

\section{Figures}



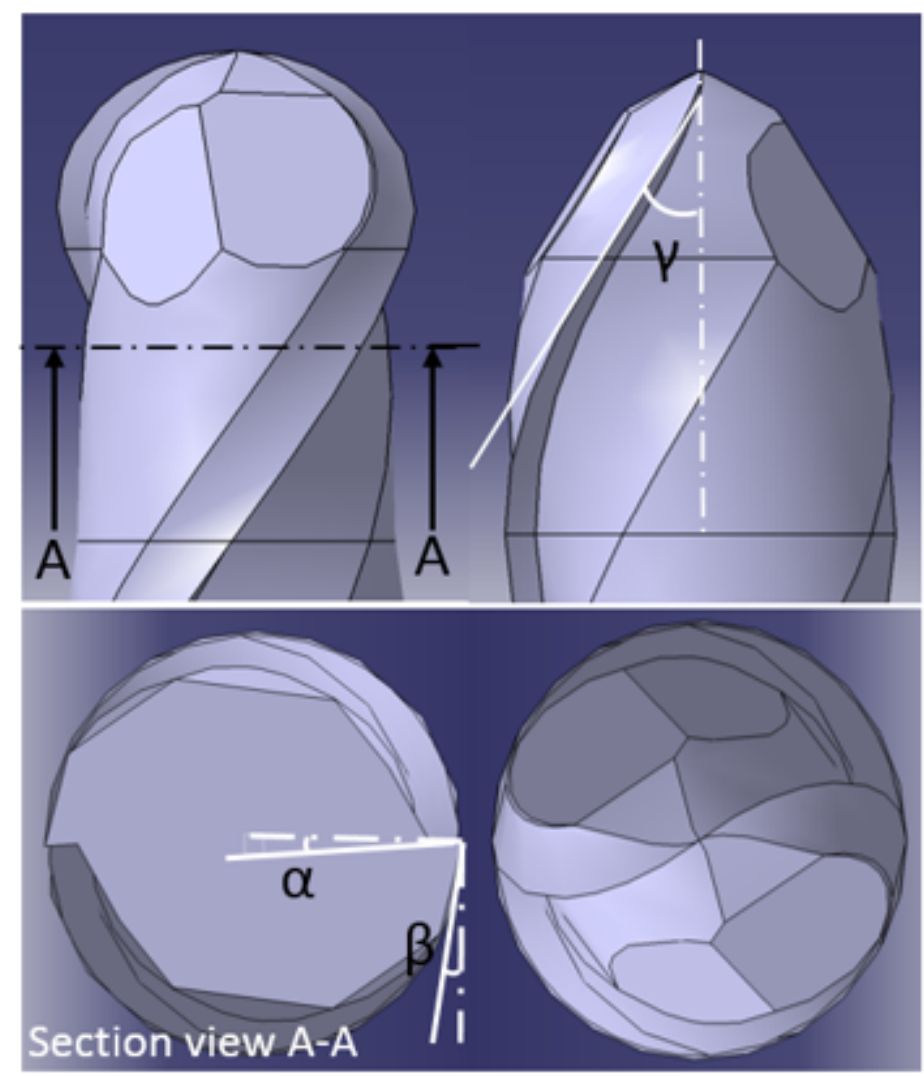

Figure 1

Ball nose end mill geometrical features

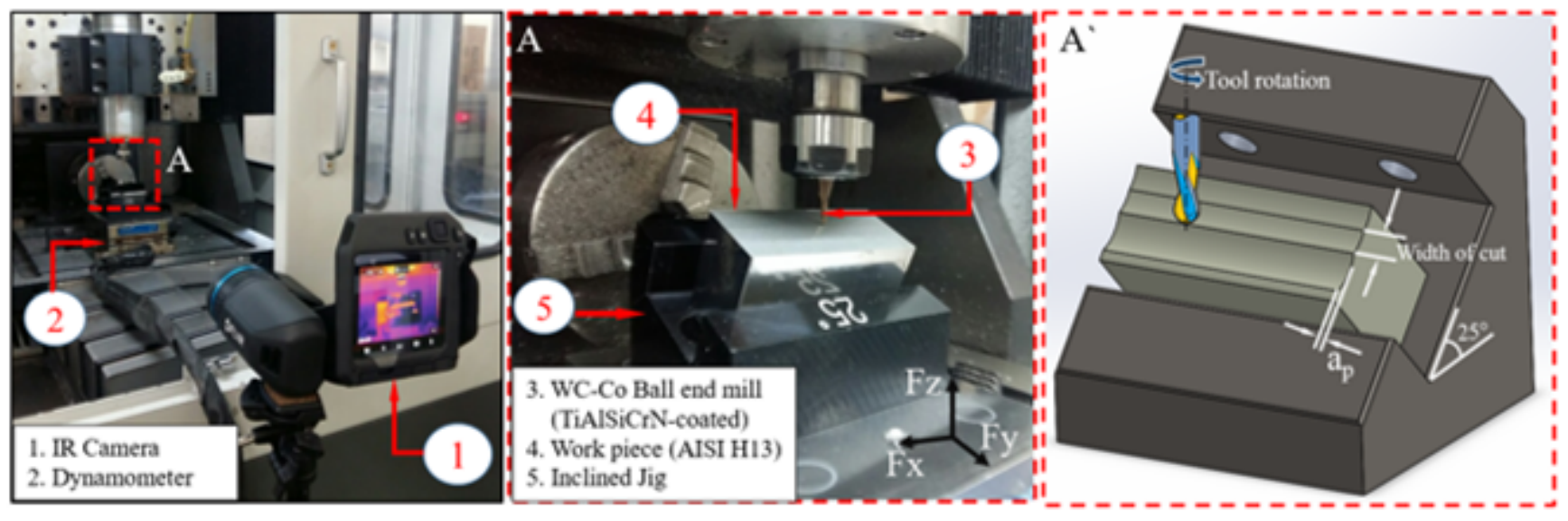

Figure 2

Experimental setup 


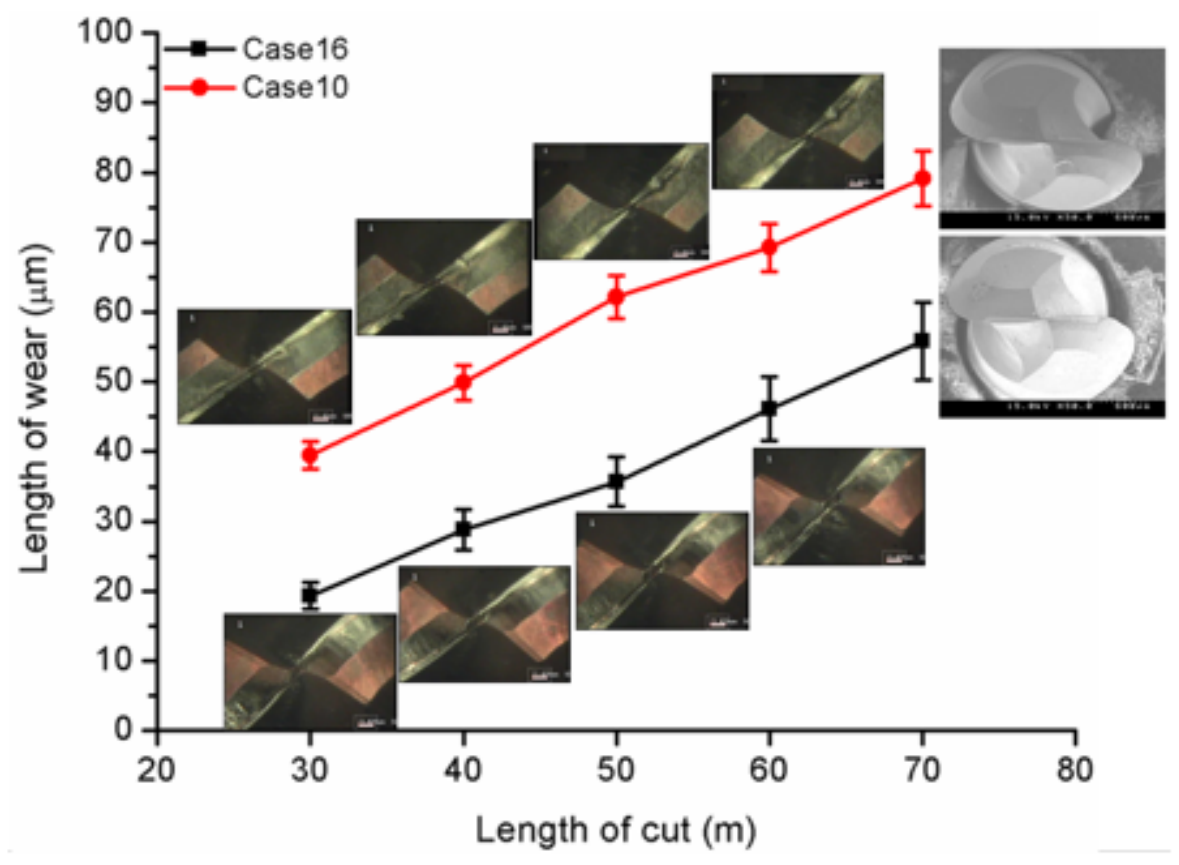

Figure 3

Length of cut vs. Length of wear
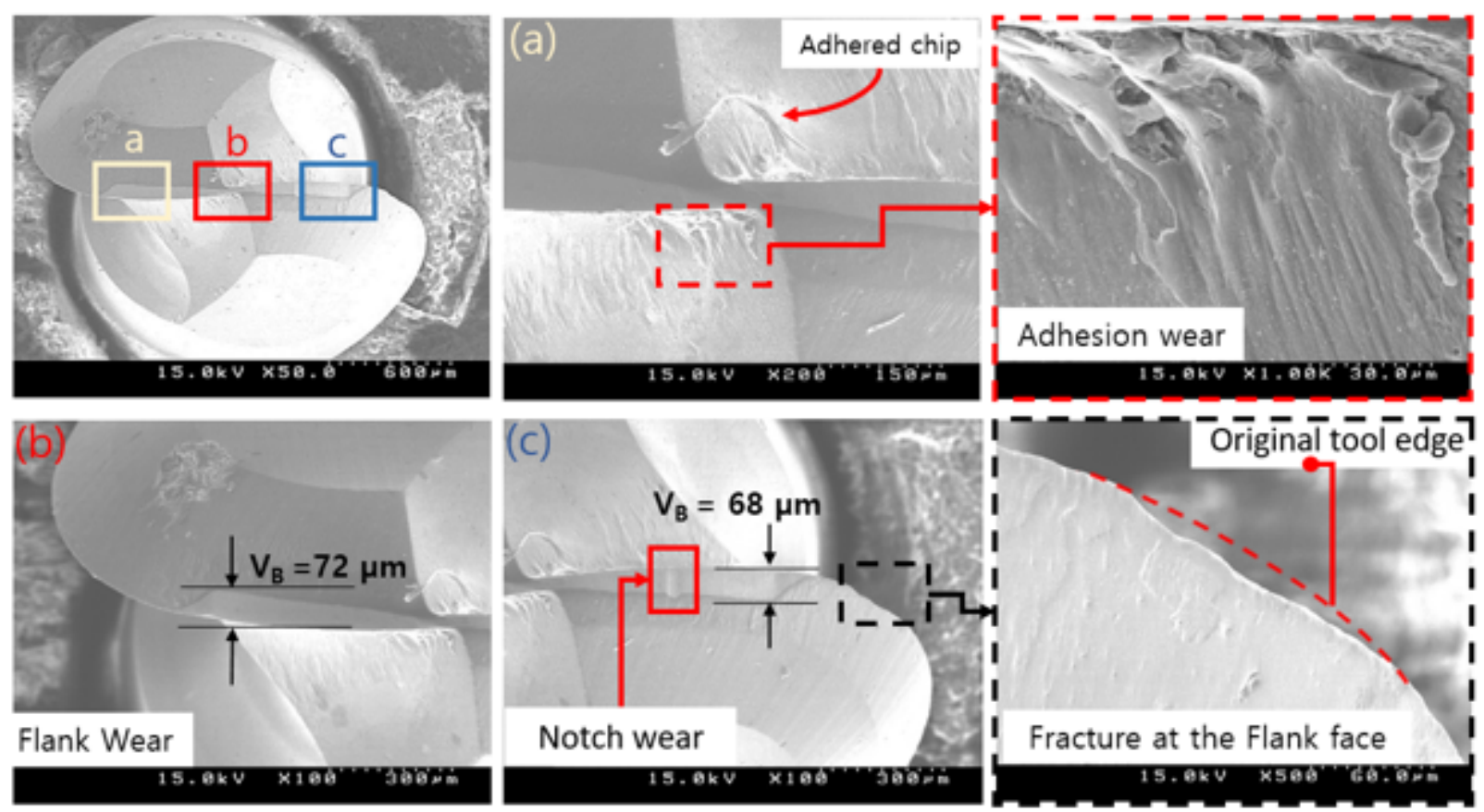

\section{Figure 4}

Wear at the cutting edge of ball end mill with geometry $9\left(\alpha=-3^{\circ}, \beta=25^{\circ}\right.$ and $\left.\gamma=36^{\circ}\right)$ 

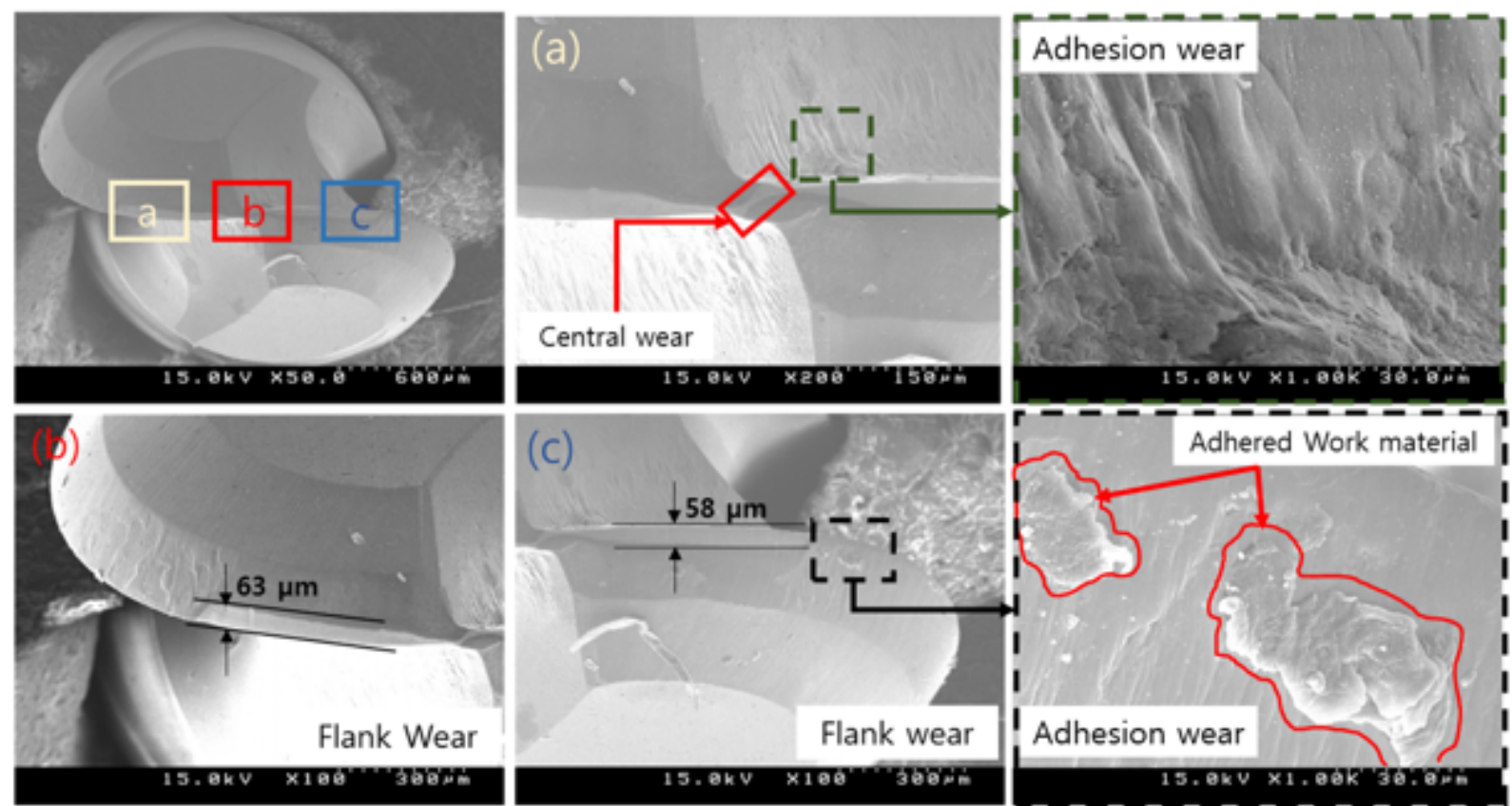

Figure 5

Wear at the cutting edge of ball end mill with geometry $16\left(a=3^{\circ}, \beta=25^{\circ}\right.$ and $\left.\gamma=24^{\circ}\right)$
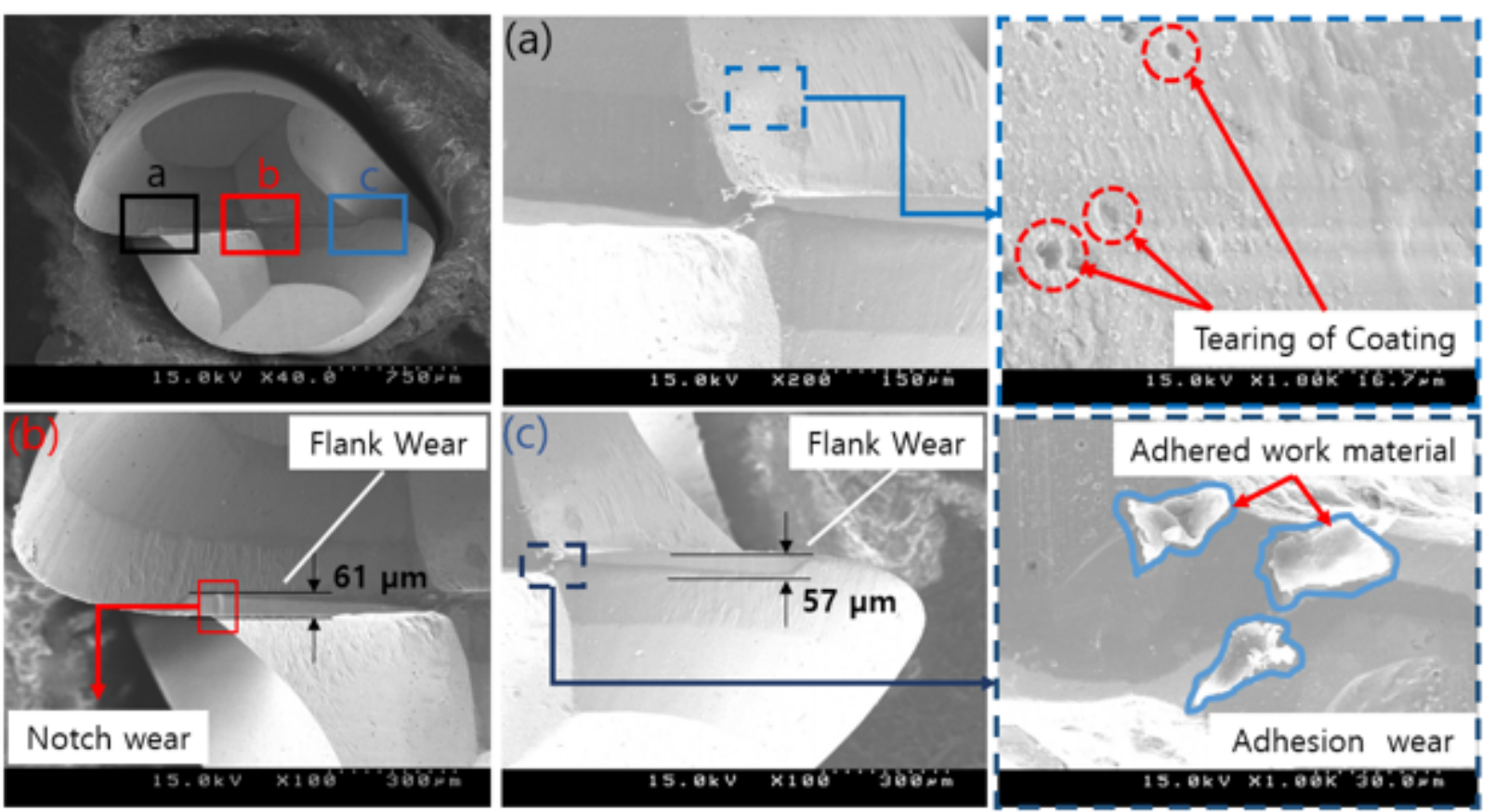

Figure 6

Wear at the cutting edge of ball end mill with geometry $19\left(a=3^{\circ}, \beta=10^{\circ}\right.$ and $\left.\gamma=32^{\circ}\right)$ 


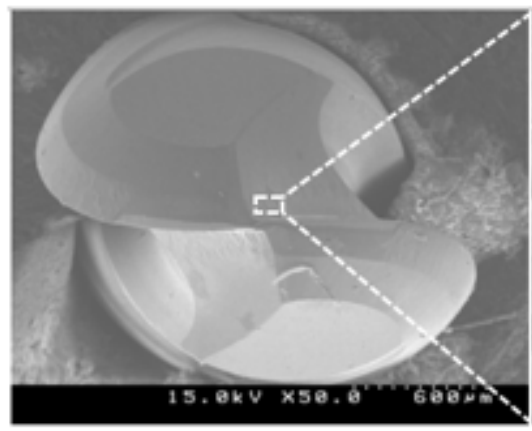

$5 \mu \mathrm{m}$

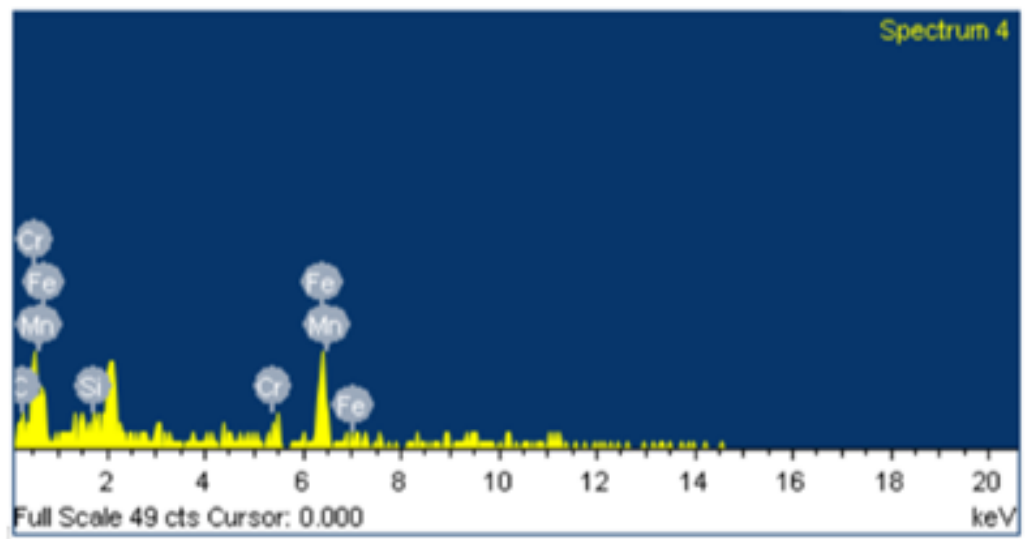

\section{Figure 7}

EDS analysis at the tool tip (geometry $16 ; \alpha=3^{\circ}, \beta=25^{\circ}$ and $\gamma=24^{\circ}$ )
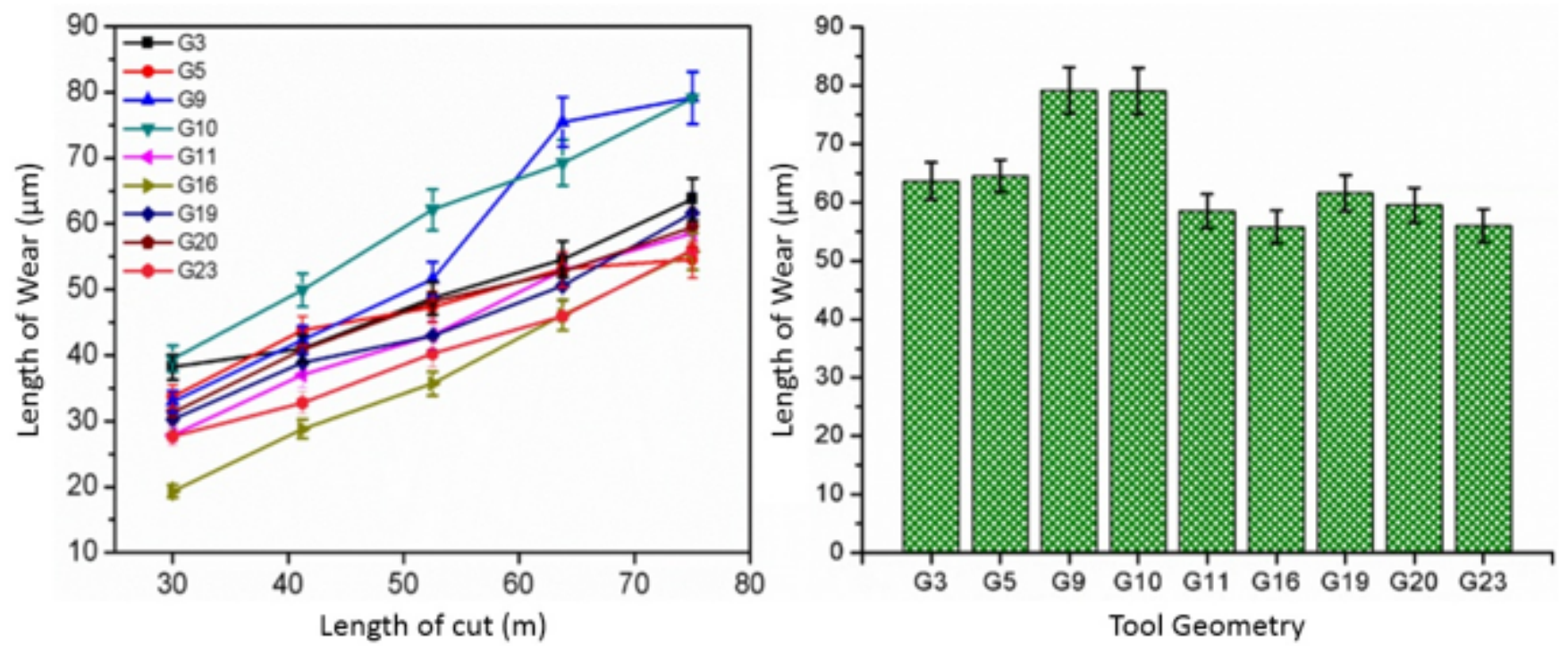

Figure 8

Tool wear (a) with increase in length of cut (b) with change in tool geometry 

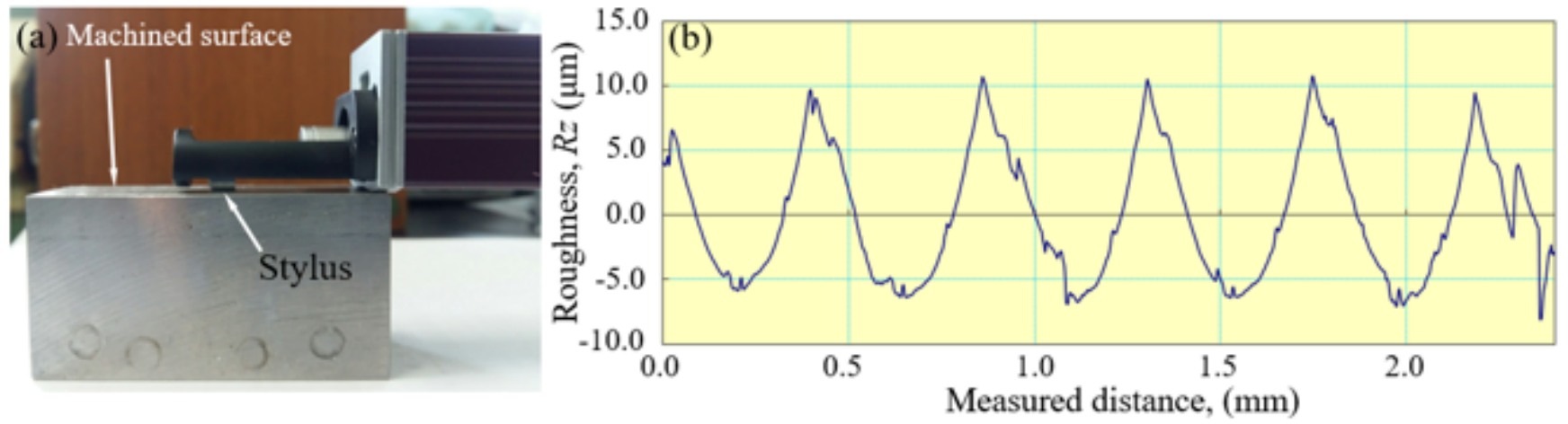

\section{Figure 9}

(a) Mitutoyo SJ-310 profilometer for surface roughness measurement, (b) Surface profile showing Rz as measured for tool geometry 11 after $30 \mathrm{~m}$ of machining length

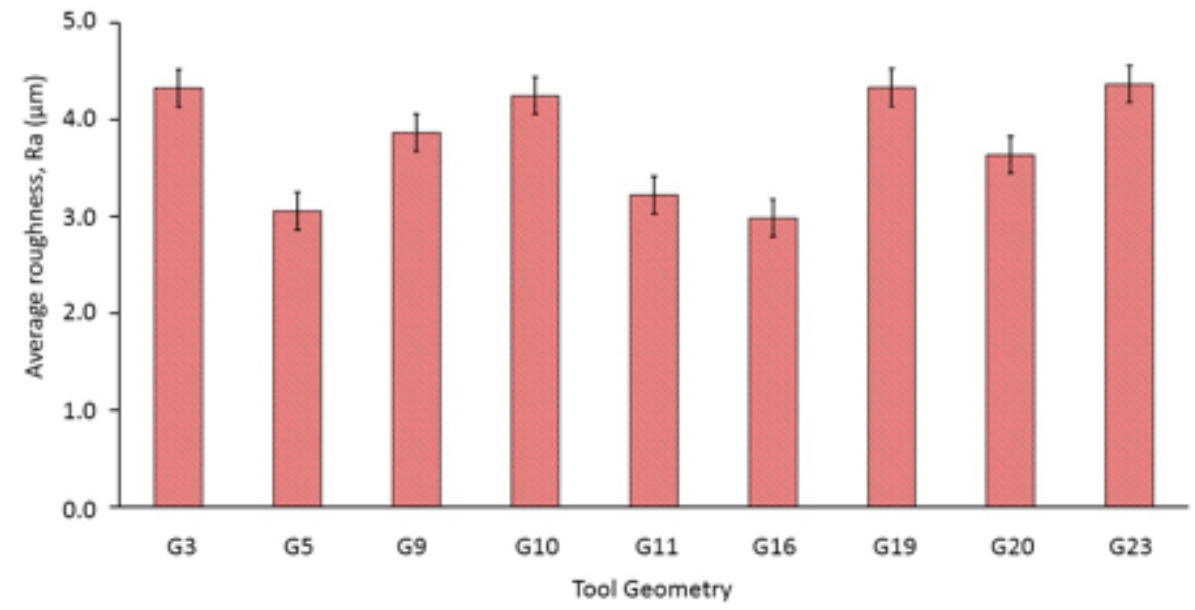

Figure 10

Surface roughness distribution with change in tool geometry 

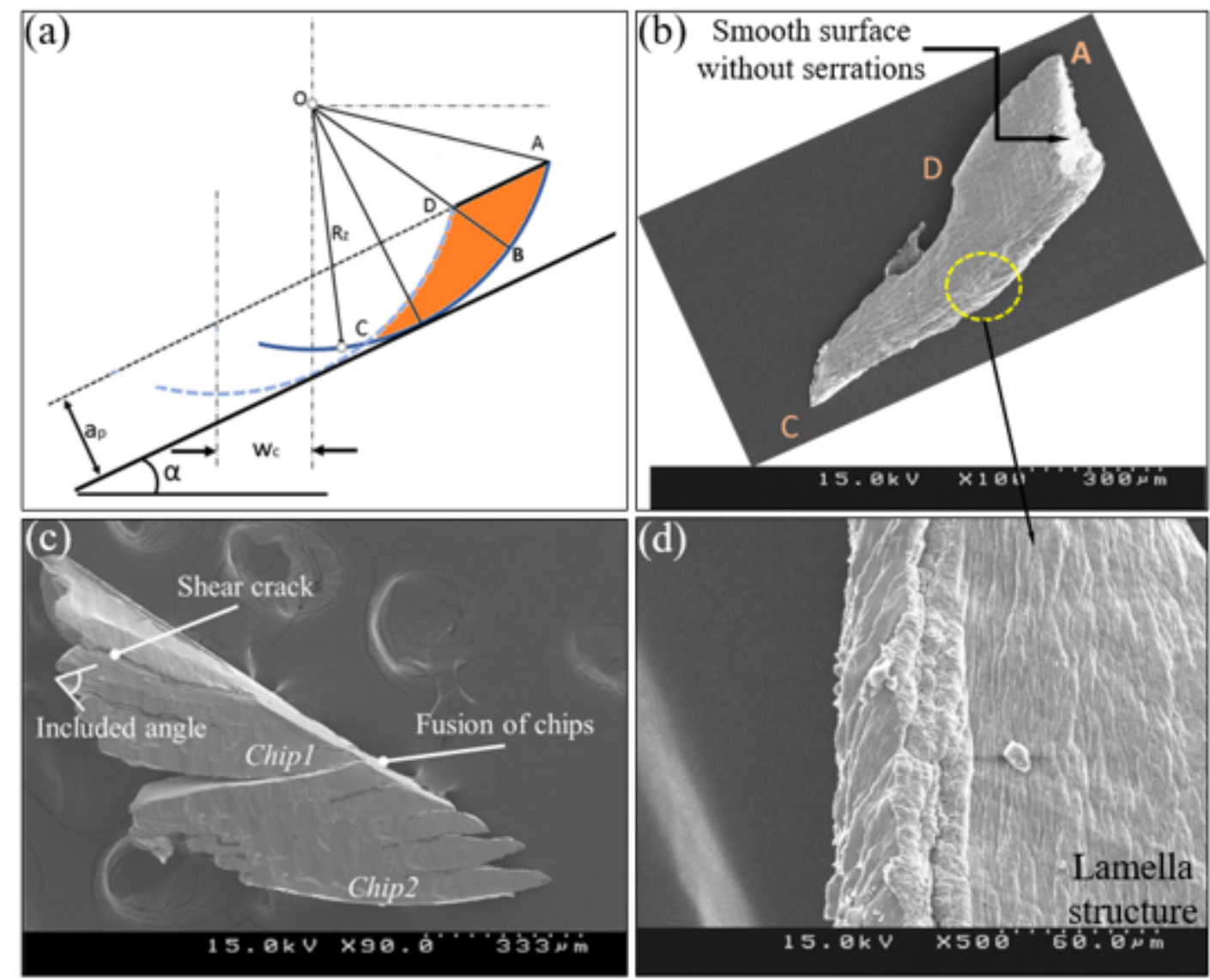

\section{Figure 11}

Chip shape (a) Theoretical, (b) ideal cutting conditions, (c) machining with worn out tool
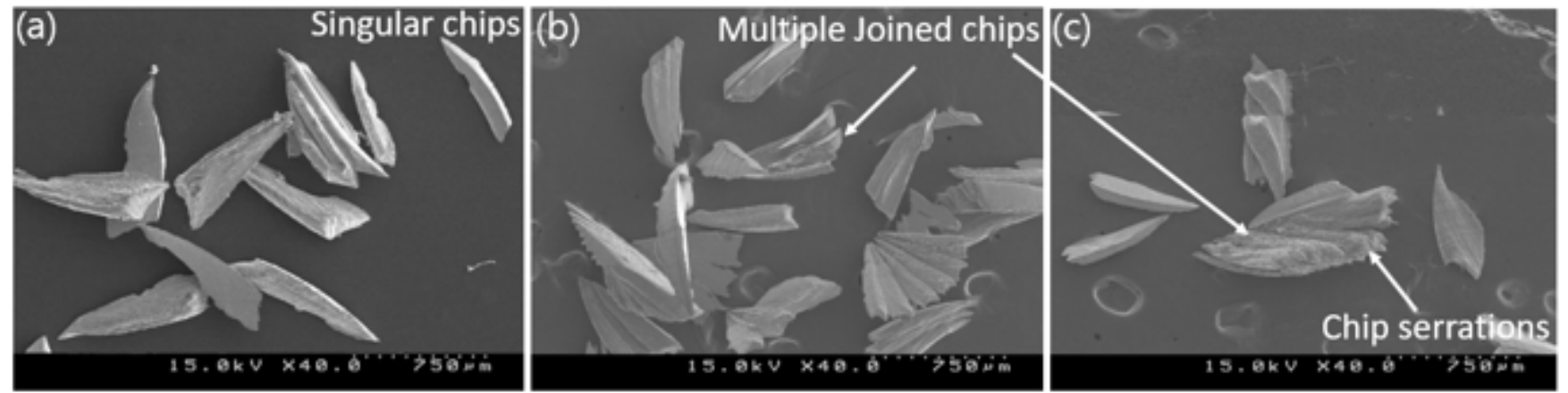

Figure 12

Chips produced during machining (a) geometry no.16 $\left(a=3^{\circ}, \beta=25^{\circ}\right.$ and $\left.\gamma=24^{\circ}\right)$,

(b) geometry no. $19\left(a=3^{\circ}, \beta=10^{\circ}\right.$ and $\left.\gamma=32^{\circ}\right)$, (c) geometry no. $\left(a=-3^{\circ}, \beta=25^{\circ}\right.$ and $\left.\gamma=36^{\circ}\right)$ 

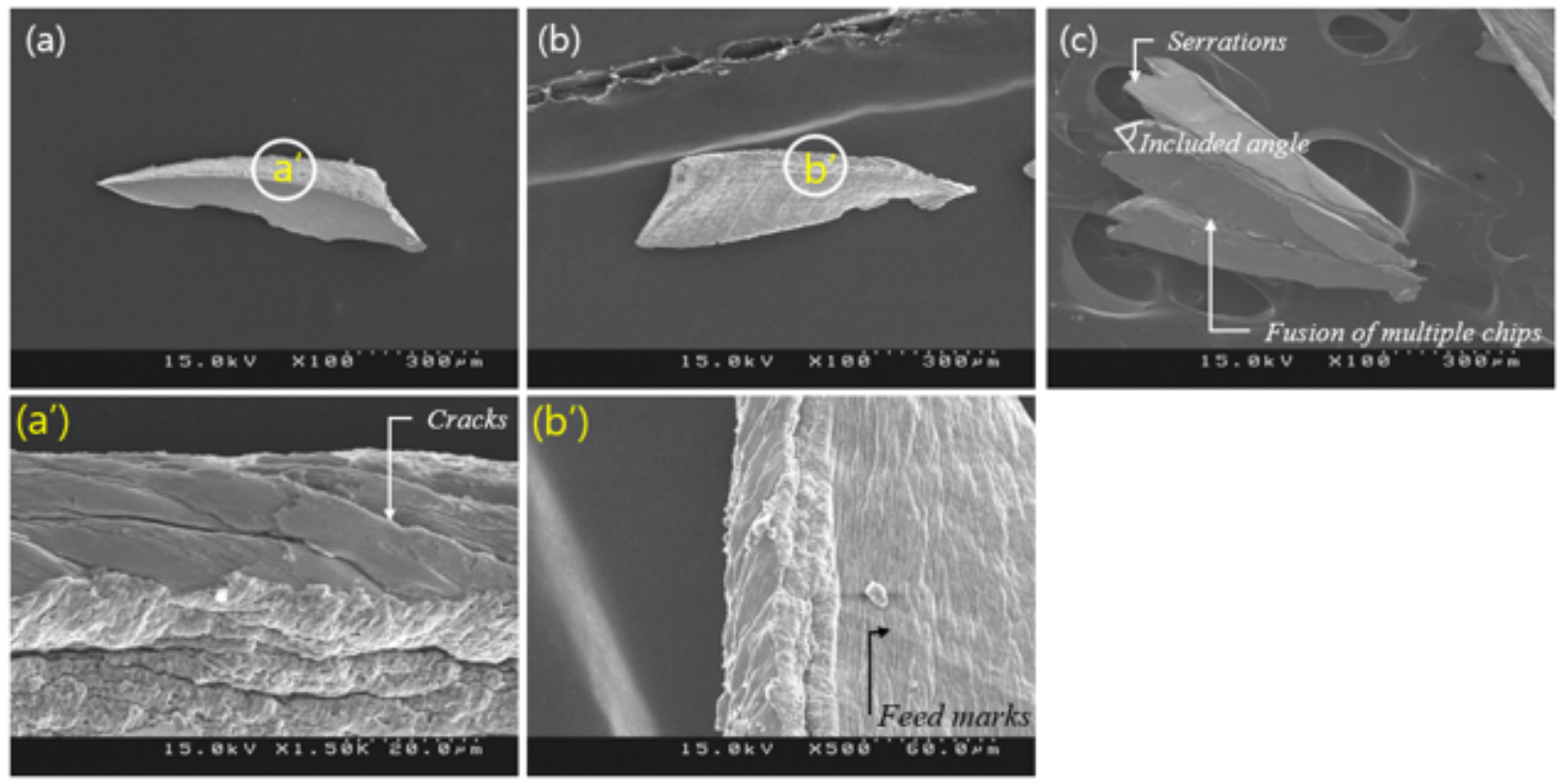

\section{Figure 13}

Chip morphology (a) geometry no.16 $\left(a=3^{\circ}, \beta=25^{\circ}\right.$ and $\left.\gamma=24^{\circ}\right)$, (b) geometry no.19 $\left(a=3^{\circ}, \beta=10^{\circ}\right.$ and $\left.y=32^{\circ}\right)$, (c) geometry no. $9\left(\alpha=-3^{\circ}, \beta=25^{\circ}\right.$ and $\left.\gamma=36^{\circ}\right)$ 